Full-text Available Online at www.ajol.info and www.bioline.org.br/ja

\title{
Elemental Concentration of Inhalable and Respirable Particulate Matter in Urban Area During Wet Season
}

\section{*11EDIAGBONYA, TF; UKPEBOR EE; OKIEIMEN, FE; MOMOH, OL; YUSUF}

\author{
${ }^{1}$. Ondo State University of Science and Technology,Okitipupa \\ ${ }^{2}$ Air Pollution Research Group, Department of Chemistry, University of Benin, Nigeria. \\ 3.Department of Environmental Engineering University of Port-Harcourt \\ E-mail: tf.ediagbonya@gmail.com,fexokieimen@yahoo.com, \\ eeukpebor@yahoo.com,yusuf_momoh@yahoo.com, Mobile Phone: +23480696066577
}

KEY WORDS: Inhalable Particle, Respirable Particle, Urban Area, Atomic Absorption Spectrophotometric, Enrichment Factor, Meteorological parameter.

\begin{abstract}
Previously, the capture of suspended particulate matter focused on the total suspended particulate matter, until recent research into the health impacts of suspended particulate matter suggests that minute particles that have toxic substances adsorbed onto their surface are insidious and deleterious for human health and vegetation. The Inhalable fraction and respirable fraction were captured between the month of May 2009 to October 2009 using SKC Air Check Gravimetric Sampler- Model 210-5000 serial No. 20537 and respirable foam for I.O.M sampler. The elemental composition (Co, Ni, $\mathrm{Zn}, \mathrm{Cu}, \mathrm{Fe}, \mathrm{Pb}$, $\mathrm{Cr}, \mathrm{Mn}$ and $\mathrm{Cd}$ ) were analyzed by using Atomic Absorption Spectrophotometric (AAS). The data generated were subjected to descriptive analysis. In inhalable fraction,the enrichment factor ranged from 1-73.3 while in respirable, it was 1- 72.9.Lead had the highest mean concentration in both inhalable and respirable fraction. From the enrichment factor $\mathrm{Cd}$ was highly enriched while $\mathrm{Pb}$ was moderately enriched. Co and $\mathrm{Ni}$ were below detection limit in both inhalable and respirable suspended particulate matter. CJASEM
\end{abstract}

http://dx.doi.org/10.4314/jasem.v18i1.11

Introduction: Precipitation is one of the most scavenging processes of particulate matter. Particulate that could possibly re-suspend are suppressed as a result of torrential down pour. This will in turn reduce the amount of trace metals in the atmosphere.

The most widespread metals in airborne particulates from the most large cities and urban areas which are usually associated with the vehicular traffic and other anthropogenic sources such as stationary fossil fuel combustion and refuse incineration plant (Pacyna and Pacyna 2001; Lee et al., 2007).

There is a direct association between atmospheric Inhalable particulate matter $\left(\mathrm{PM}_{10)}\right.$ and people's health (Schwartz et al .,1996). Exposure to increased $\mathrm{PM}_{10}$ shows a high correlation with increase of respiratory diseases pulmonary damage and mortality among the population (Ilabaca et al 1999, Harrison and Yin 2000; Cifuentes et al., 2000).
Respirable fraction (fine fraction) of particulate matter (PM2.5 and less) are retained in the alveolar region of the lungs and are able to diffuse into the blood circulation, and may subsequently induce inflammation, oxidative stress (Soeren Sen et al., 2003), and increased coagulation of the blood (Segaton et al., 1995).

Consequently, the study is designed to obtain a baseline concentration of the trace metal in respirable and inhalable suspended particulate matter and to compute the enrichment factors.

Apart from the deleterious effect of particulate matter on health, it also reduces visibility and plays an important role in the deterioration of monuments and buildings. The particulate matter impact on climate is primarily a cooling effect due to increased scattering to space as the atmospheric particulate matter burden increases. According to IPCC 2001, the overall cooling by particulate matter may counter balancing global warming by green house gases and its effect on cloud condensation (Levin et al., 2003). 


\section{MATERIALS AND METHOD}

The town Sapele is situated in the south-south geopolitical region of Nigeria with a population of about 135,800 (NPC 2005/2006). It was once an integral part of the old western region of Nigeria. It is presently a part of Delta State of Nigeria created in August 27, 1991, after having been part of the defunct Mid Western State (1963-1976) and the defunct Bendel State (1976-1991)

This study area is located within the co-ordinates of latitude $005^{0} 500^{\prime} 0^{\prime \prime}-005^{0} 560 " \mathrm{~N}$ and longitude $005^{0} 37^{\prime} 0^{\prime \prime}-005^{\circ} 45^{\prime} 0^{0} \mathrm{E}$. The study area has a total aerial extent of 165.25 square kilometers.

Sapele is located near the junction of Jamieson and Ethiope rivers and about 80 mile (144 kilometers) from the sea, well closer into the timber yielding forest of the interior. Sapele is one of the first-rate wood industries in this region.

However, it is a commercial city with four petroleum and allied industries. The climate is tropical with two distinct seasons, wet and dry.

The major activities among the people of Sapele that generate particulate pollution are usually bush burning as a pre planting preparation, welding and vulcanizing combustion of solid waste as a means of waste disposal, gas flaring, re-suspension of dust from unpaved road, and the production of charcoal which involves the burning of wood in an open space from dawn till dusk in four different locations in the city. These charcoal are usually exported to other countries and sometime nearby cities.

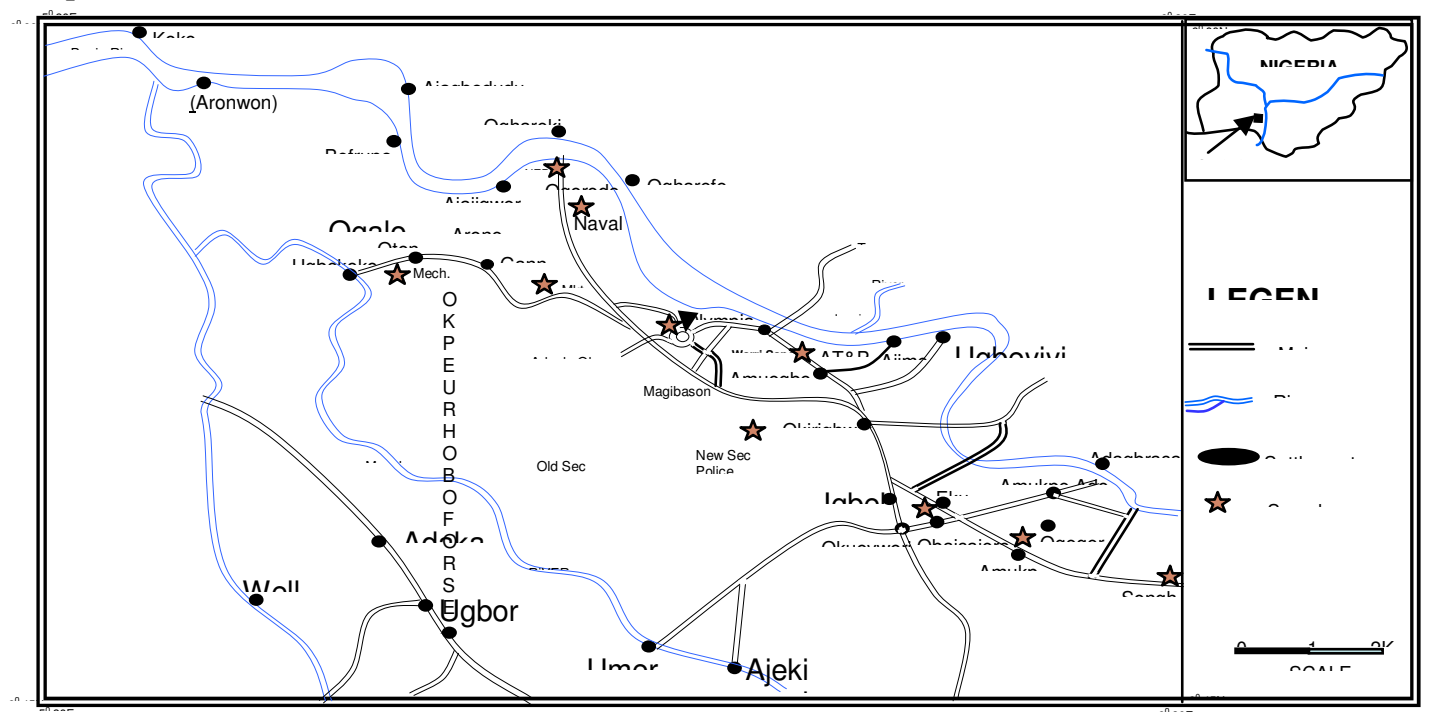

Fig.1: Map of Sapele Reflecting the various Sampling locations.

Table 1: The site coordinates and description

\begin{tabular}{|c|c|c|c|}
\hline $\mathbf{S} / \mathbf{N}$ & Site code & Co-ordinates & Site description \\
\hline 1 & SP.MV & $\begin{array}{l}\text { N05'51'53.5" } \\
\text { E005'41'39.0" }\end{array}$ & The site was created at the mechanic village (shell Rd) \\
\hline 2 & SP.SG & $\begin{array}{l}\text { N05 } 51^{\circ} 025^{\prime \prime} \\
\mathrm{E}^{\circ} 05^{\circ} 44^{1} .37 .4\end{array}$ & This was created at the Songhai \\
\hline 3 & SP.NOR & $\begin{array}{l}\text { N05'51'06." } \\
\text { E005 44'45.4" }\end{array}$ & The site was created at new Ogorode Road. \\
\hline 4 & SP.RH & $\begin{array}{l}\text { N05 } 51^{\prime} .33 . " \\
\text { E005 } 43^{\prime} 06.4^{\prime \prime}\end{array}$ & The site was created at residential houses in Amoukpe area \\
\hline 5 & SP.OJ & $\begin{array}{l}\text { N05 } 53^{\prime} 24.8^{\prime \prime} \\
\text { E}^{\prime} 05^{\circ} 40^{\prime} 4.9^{\prime \prime}\end{array}$ & The site was created at Olympia Junction \\
\hline 6 & SP.SM & $\begin{array}{l}\text { N05 } 544^{\prime} 05.9^{\prime \prime} \\
\text { E}^{\circ} 45^{\circ} 41^{\prime} 89^{\prime \prime}\end{array}$ & The site was created at Sapele market \\
\hline 7 & SP.IA & $\begin{array}{l}\mathrm{N}^{\circ} 5^{\circ} 55^{\prime} 16.8^{\prime \prime} \\
\mathrm{E}^{\prime \prime} 5^{\circ} 38^{\prime} 48.5^{\prime \prime}\end{array}$ & The site was created at the industrial area \\
\hline 8 & SP.NER & $\begin{array}{l}\text { N05'52 28.6" } \\
\text { E005 }^{\circ} 42^{\prime} 07.8^{\prime \prime}\end{array}$ & This was created at New Eku Road \\
\hline 9 & SP.SWR & $\begin{array}{l}\text { N05'52'28.6" } \\
\text { E005'42 07.8" }\end{array}$ & The site was created at Warri Sapele Road \\
\hline 10 & SP.OK & $\begin{array}{l}\text { N05 } 522^{\circ} 27.0^{\prime \prime} \\
\text { E005 }^{\circ} 43^{\prime} 40.7^{\prime \prime}\end{array}$ & The site was created at Okirighwere \\
\hline
\end{tabular}


In line with the objectives of the study, ten monitoring sites were carefully selected to represent all the quarters of the city with high air pollution sources. These sites were created within the vicinities to reflect variation in traffic volume and human activities. Table 1 represents the monitoring sites and their co-ordinates. The monitoring sites were Georeferenced by using GARMin GPS MAP 765 chart plotting receiver

Sample Collection: SKC Aircheck XR5000 high volume Gravimetric sampler and the I.O.M multi fraction dust sampler (Institute of Occupational Medicine). The I.O.M (Institute of occupation Medicine Edinburgh) multi fraction dust sampler uses $25 \mathrm{~mm}$ diameter filter for inhalable dust sampling it is a flexible sample head which can be with foam to give a respirable measurement. The filter and cassette rear was pre-weighed to determine the initial respirable dust, while the filter, foam and whole cassette together was pre-weighed to determine the initial inhalable. After sampling, the filter foam, and the whole cassette together was reweighed to determine the inhalable fraction. Then the whole cassette was split. In order to weigh the cassette rear and filter only to determine the final weight of the respirable fractions the particles were collected at a flow rate of $2 \mathrm{~L} / \mathrm{min}$ for eight hours and the sampler was placed between height of $1.5 \mathrm{~m}-2 \mathrm{~m}$ of human. The difference between the final weights and initial weight is the amount of respirable and inhalable dust collected. The sampling was done from May 2009-Oct 2009.

The concentration in $\mu \mathrm{g} / \mathrm{m}^{3}$ was calculated by

Final weight $(\mathrm{mg})$ - initial weight $(\mathrm{mg}) \times 1000$

Flow rate $\left(\mathrm{m}^{3} / \mathrm{min}\right) \times$ sampling period $(\mathrm{min})$

Sample Digestion And Measurement: The trace metals $\mathrm{Pb}, \mathrm{Cd}, \mathrm{Ni}, \mathrm{Cu}, \mathrm{Co}, \mathrm{Fe}, \mathrm{Zn}, \mathrm{Cr}$ and $\mathrm{Mn}$ were determined by AAS (Thermo electron corporation Atomic Absorption spectrometry, S. Series) A portion of the effective filter and respirable foam were digested separately with $20 \mathrm{ml} 1: 1 \mathrm{HNO}_{3}$ in a beaker and covered with a watch glass which was concentrated to about $5 \mathrm{ml}$ on a hot plate at 150 $180^{\circ} \mathrm{C} .10 \mathrm{ml}$ of $1: 1 \mathrm{HNO}_{3}$ was added to repeat it. The extract was filtered through a 541 filter paper, the filter paper and the beaker was washed with $0.25 \mathrm{M}$ $\mathrm{HNO}_{3}$. The filtrate was transferred and washed into $50 \mathrm{ml}$ volumetric flask. The chemical and reagents used for analysis were analar grade.(Harrison,1986)

Data Analysis: The results gotten from this work were subjected to descriptive statistics and enrichment factor computation. In this work, Iron was chosen as the reference element during the computation of enrichment factor. Jian et al., (2004), Ukuo and Udiokwere.,(2005) used Iron as a reference.

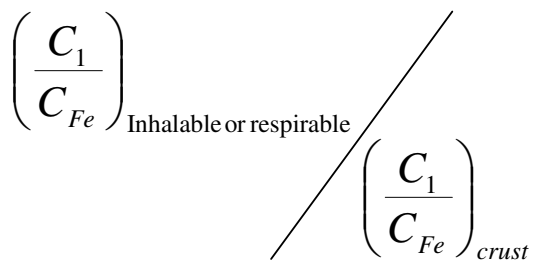

where $C_{1}$ is the concentration of the element considered in the Inhalable or respirable of the crust and $C_{F e}$ is the concentration of the reference element $(\mathrm{Fe})$.Iron was chosen as reference element because is one of numerous crustal elements for the computation of enrichment factor

The elemental concentration in the crust used in this study was got from Wedephol 1968. An enrichment factor close to 1 indicates that the relative concentration of a given element is identical to that which is present in the soil. An enrichment factor greater than 1 indicates that the element is more abundant in the air relative to that found in the soil, while values less than 1 suggests a depletion of the element in the air over that found in soil.

\section{RESULTS AND DISCUSSION}

The major sources of $\mathrm{Cd}$ are metal industries engage in extraction, refining, machine, electroplating and welding of Welding of Cadmium materials. By product of refining Lead, Zinc and Copper pesticides, fertilizers, Cadmium - Nickel batteries, reactor poising in nuclear fission plants and in production of tetraethyl lead gasoline. The Chronic and acute poisoning inhalation of fumes and vapors of $\mathrm{Cd}$ cause damage to the kidney, emphysema, bronchitis, cancer, gastric and intestinal disorder, disease of the heart, liver and brain. While the major sources of $\mathrm{Pb}$ are automobile emission, lead smelters, combustion of coal, fuel oil and lead - arsenate pesticides. $\mathrm{Pb}$ is absorbed through gastro-intestinal respiratory tract and deposited in mucous membrane of nose, throat and in the lung.

The World Health Organization (WHO) has established air quality guidelines (WHO, 2000) similarly European Union has set annual limits on selected trace metals such as $500 \mathrm{ng} / \mathrm{m}^{3}$ for $\mathrm{Pb}$, $6 \mathrm{ng} / \mathrm{m}^{3}$ for As, Ni $20 \mathrm{ng} / \mathrm{m}^{3}$ and $\mathrm{Cd} 5 \mathrm{ng} / \mathrm{m}^{3}$.

Table 1 shows the mean concentration of trace metals in inhalable suspended particulate matter while Table 
2 shows the mean concentration of respirable suspended particulate matter. From the analysis Co and $\mathrm{Ni}$ were below detection limits.

Tables 3 and 4 show the descriptive statistics and the enrichment factor for inhalable and respirable suspended particulate matter respectively. The total mean concentration values of the analyzed trace metals follow the order: $\mathrm{Pd}>\mathrm{Fe}>\mathrm{Cr}>\mathrm{Cd}>\mathrm{Cu}>\mathrm{Zn}$.

From Table 3, Cd is highly enriched while $\mathrm{Pb}$ is moderately enriched. While in the respirable concentration $\mathrm{Cd}$ was also highly enriched and $\mathrm{Pb}$

Table 2 : Descriptive Statistic of Inhalable Suspended

Particulate Matter and Enrichment Factor during

Wet Season in Sapele

\begin{tabular}{llllll}
\hline & Min & Max & Mean & SD & Enrichment factor \\
\hline $\mathrm{Fe}$ & 0.23 & 0.68 & 0.32 & 0.16 & 1 \\
$\mathrm{Zn}$ & 0.04 & 0.04 & .0378 & 0.00 & 0.569 \\
$\mathrm{Cu}$ & 0.04 & 0.04 & .0410 & 0.00 & 1.686 \\
$\mathrm{Mn}$ & $\mathrm{BDL}$ & $\mathrm{BDL}$ & $\mathrm{BDL}$ & $\mathrm{BDL}$ & - \\
$\mathrm{Cd}$ & 0.05 & 0.05 & 0.05 &. & 581.571 \\
$\mathrm{~Pb}$ & 0.85 & 1.69 & 0.94 & 0.26 & 73.320 \\
$\mathrm{Cr}$ & 0.17 & 0.23 & 0.20 & 0.0258 & 3.612 \\
$\mathrm{Ni}$ & $\mathrm{BDL}$ & $\mathrm{BDL}$ & $\mathrm{BDL}$ & $\mathrm{BDL}$ & $\mathrm{BDL}$ \\
$\mathrm{Co}$ & $\mathrm{BDL}$ & $\mathrm{BDL}$ & $\mathrm{BDL}$ & $\mathrm{BDL}$ & $\mathrm{BDL}$ \\
\hline $\mathrm{BDL}$ & $=\mathrm{Bellow}$ & Detection Limit
\end{tabular}

was moderately enriched. The data obtained in this study is compared with data from previous studies by other authors (Ukuo and Ndiokwere ,2005; Chow et al.,1994;Dongarra et al 2007;Obioh et al 2005; Yele et al., 2004;Martin et al., 2007). Figure 2 shows the comparison of Mean inhalable and respirable for the different trace metals; from it we see that $\mathrm{Pb}$ has the highest concentration. The mean of the three meteorological parameters measured in this work. The mean ambient temperature was in the range of $27.9-29.9^{\circ} \mathrm{C}$, the relative humidity was in the range of $75-85 \%$ and the mean wind speed was in the range of $0.85-0.95 \mathrm{~m} / \mathrm{s}$.

Table 3: Descriptive Statistics of Respirable Suspended Particulate Matter and Enrichment Factor during Wet Season in Sapele

\begin{tabular}{llllll}
\hline & Min & Max & Mean & SD & $\begin{array}{l}\text { Enrichment } \\
\text { factor }\end{array}$ \\
\hline $\mathrm{Fe}$ & 0.23 & 0.35 & 0.2675 & 0.05560 & 1 \\
$\mathrm{Zn}$ & 0.04 & 0.04 & 0.0370 &. & 0.513 \\
$\mathrm{Cu}$ & 0.04 & 0.05 & 0.0440 & 0.00361 & 1.490 \\
$\mathrm{Mn}$ & $\mathrm{BDL}$ & $\mathrm{BDL}$ & $\mathrm{BDL}$ & $\mathrm{BDL}$ & $\mathrm{BDL}$ \\
$\mathrm{Cd}$ & 0.05 & 0.05 & 0.0460 & 0.00000 & 570.960 \\
$\mathrm{~Pb}$ & 0.86 & 0.90 & 0.8763 & 0.01553 & 72.900 \\
$\mathrm{Cr}$ & 0.16 & 0.20 & 0.1800 & 0.02828 & 3.430 \\
$\mathrm{Ni}$ & $\mathrm{BDL}$ & $\mathrm{BDL}$ & $\mathrm{BDL}$ & $\mathrm{BDL}$ & $\mathrm{BDL}$ \\
$\mathrm{Co}$ & $\mathrm{BDL}$ & $\mathrm{BDL}$ & $\mathrm{BDL}$ & $\mathrm{BDL}$ & $\mathrm{BDL}$ \\
\hline \multicolumn{5}{c}{$\mathrm{BDL}=\mathrm{Below}$ Detection Limit }
\end{tabular}

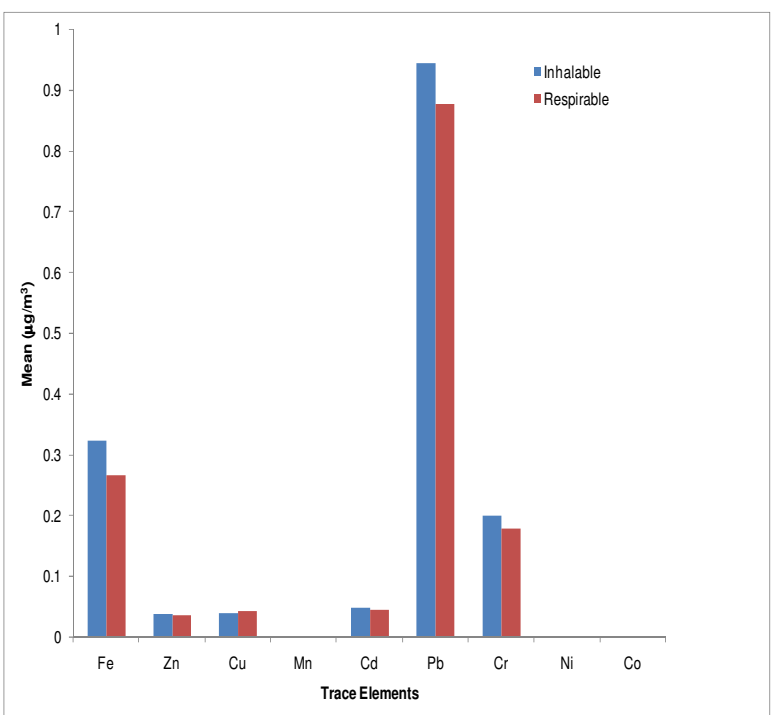

Fig 2: Mean comparison of Inhalable and respirable Suspended particulate matter of the different trace metals.

Conclusion In this work, the trace metal concentration of some toxic heavy metal such as Co, $\mathrm{Ni}, \mathrm{Cu}, \mathrm{Pb}, \mathrm{Zn}, \mathrm{Mn}, \mathrm{Fe}, \mathrm{Cr}$ and $\mathrm{Cd}$ were analyzed for. From the enrichment factor $\mathrm{Cd}$ was highly enriched while $\mathrm{Pb}$ was moderately enriched. $\mathrm{Co}$ and $\mathrm{Ni}$ were below detection limit in both inhalable and respirable suspended particulate matter. Anthropogenic activities are the major sources of these trace metals in the atmosphere. 
Acknowledgement. We gratefully acknowledge the support of Mr. Ufuoma Asagba, Dr. Magnus Legmah, Dr.Mrs. Justina Ukpebor, Mr. Eddy Olumese, Mr. Obozakhai, Mr. Okungbowa Godwin Nosa for their immeasurable assistance.

\section{REFERENCES}

Chow, J.C., Watson, J.G., Fujuta, E.M., Lu, Z., Lawson, D.R. (1994) Temporal and spatial variations of PM2.5 and PM10aerosol in the southern California air quality study. Atmospheric Environment, 28,2061-2080.

Cifuentis, L., Vega, J. Kopfer, K., (2000) Effect of the fine fraction of particulate matter versus coarse mass and other pollutants on daily mortality in Santiago, Chile. Journal of Air and Waste Management Association 50, 1287-1298.

Dongarra,G,Manno E,Varrica D,Vultagio M (2007) mass levels Crustal Component and trace elements in $\mathrm{Pm}_{10}$ in Palermo, Italy, Atmospheric Environment 41, 7977 $-7986$.

Harrison,R.M (1986), Metal analysis in handbook of air pollution aanysis ,R.M.Harrison and R.Perry(eds),Chapman\&Hall,London,215-277

Harrison, R. Yin, J. (2000): Particulate matter in the atmosphere: which particle properties are important for its effects on health? This Science of Total Environmental 249, 85-101.

Ilabaca, M., Olaeta I. Campos, E. Villain J., Tellez-Rojo, M.M., Romieu, J.J. (1999): Association between level of fine particulate and emergency visits for Pneumonia and other respiratory illness among children in Santiago, Chile. Journal of Air and Waste Management Association 49, 154-16.

IPPC: (2001): Inter governmental panel on climate change. Third Assessment Report Cambridge University Press, Cambridge, U.K.

Jian Zheng ${ }^{\mathrm{ab}}$, Mingguang Tan ${ }^{\mathrm{a}}$, Yasuyuki Shibata ${ }^{\mathrm{a}}$, Atsushi Tanaka ${ }^{\mathrm{b}}$, Yun $\mathrm{Li}^{\mathrm{a}}$, Guilin Zhang ${ }^{\mathrm{a}}$, Yuanmao Zhang ${ }^{\mathrm{c}}$, Zuci Shan ${ }^{c}$ (2004). Characteristic of Lead isotope ratios and elemental concentration in $\mathrm{PM}_{10}$ fraction of air borne particulate matter in Shanghai after the phase out of leaded gasoline, Atmospheric environment 38, $1191-1200$

Lee, C.S.L.Li. X-D, Zhang, G. Li. J. Ding A-J Wang T. (2007) Heavy metals and $\mathrm{Pb}$ Isotopic composition in urban and suburban areas of Hong Kong and Guangzhou South China. Evidence of the long range transport of air contaminants Atmospheric Environment 41, 432-447.
Levin, Z. Teller, A. Ganor E. Graham, B. Andreae, M.O. Maenhaut, W. Falkovich, A. H., Rudich, Y. (2003) Role of aerosol size and composition in nucleation scavenging within clouds in a shallow cold front. Journal of Geophysical Research 108 (D22) 4700.

Martin Branij Marketa Doinsova, Pavla Rezacova (2007) particulate air pollution in a small settlement. The effect of local heating Applied Geochemistry 22, 1255 -1264 .

NPC (2005/2006). National Population Commission Census

Obioh, I.B,Olise F.S,Owoade O.K and Olaniyi H.B (2005) Chemical Characterization of suspended Particulate along air corridors of motorways in two Nigeria C ities Journal of applied science 5(2) 347-350.

Okuo, James M. and Ndiokwere, C. L. (2005). Elemental concentration of total suspended particulate matter on relation to air pollution in Niger Delta: A Case Study of Warri: Trends in Applied Science Research 1(1): 91-96.

Pacyna, J.M., Pacyna, E.G. (2001): An assessment of global and regional emissions of trace metals to the atmosphere from anthropogenic sources worldwide. Environmental Review 9 (4) 269-298.

Schwartz, J., Dockery D., Neas, L. (1996) Is daily mortality associated specifically with five particles? Journal of Air and Waste Management Association 46, 2-14.

Seaton D. Godden, W. MacNee, Donaldson, acute health effects Lancet 345, 176-178

Soerensen, M. Autrup H. Moller, P. Hertel, O. Solvang. S. Vinzents, P. Knudsen L.E. Loft S. (2003): Linking exposure to environmental pollutants with biological effects, Mutat, Res. 544, 255-271.

Wedephol, K. H. (1968). Origin and Distribution of the Elements p99, L. H. Ahren ed; Pergamon press, London, England.

WHO (2000). Air Quality Guidelines for Europe. World Health Organisation: Regional Office for Europe: Copenhagen, p273, ISBN 29 890, 13583.

Guoshun Zhuang, Ying Wang, Lihui Han Jinghua, Guo Mo Dan, Wenjie Zhang, Zifu Wang, Zhengping Hao (2004). The air-borne particulate pollution in Beijing concentration, composition distribution and sources. Atmospheric Environment 38, 5991-6004. 